\title{
Evolution of the HIV-1 protease region in heavily pretreated HIV-1 infected patients receiving Atazanavir
}

\author{
Barbara Vergani ${ }^{\text {a }}$, Mirko Lo Cicero a ${ }^{\text {, Ottavia Vigano' }}{ }^{\text {a }}$, Francesca Sirianni ${ }^{\text {a }}$, \\ Stefania Ferramosca ${ }^{a}$, Paola Vitiello ${ }^{a}$, Paola Di Vincenzo ${ }^{a}$, Maria Pia De Pasquale ${ }^{b}$, \\ Massimo Galli ${ }^{\text {, }}$, Stefano Rusconi ${ }^{\mathrm{a}, *}$ \\ a Sezione di Malattie Infettive e Immunopatologia, Dipartimento di Scienze Cliniche "Luigi Sacco", \\ Universita' degli Studi, Milano, Italy \\ ${ }^{\mathrm{b}}$ Vanderbilt University School of Medicine, Division of Infectious Diseases, Nashville, USA \\ Received 22 June 2007; received in revised form 27 September 2007; accepted 4 October 2007
}

\begin{abstract}
Background: Previous in vitro studies indicated that Atazanavir (ATV) has a distinct resistance profile than other protease inhibitors (PIs). In treatment-experienced patients ATV resistance is characterised by the accumulation of at least four mutations among those that confer cross-resistance to the PIs.

Objective: We studied the evolution of PIs resistance mutations in 10 HAART-failed patients undergoing ATV enrolled in an early access program.

Study design: Virus genotypic resistance was determined from plasma collected at baseline and during treatment. HIV-RNA was extracted and the pol region amplified and sequenced. Genotypic data were used to determine drug susceptibility. Phylogenetic analysis was performed. Results: At baseline, genotypic data showed cross-resistance patterns to approved PIs in 6 patients. In two of these subjects new mutations (I54V and A71V) conferring cross-resistance emerged after 3 months of therapy. The I50L mutation was evidenced in one subject after 12 months of treatment. The "virtual" phenotype analysis mirrored the resistance profiles to ATV and other PIs and evidenced differences with tipranavir and darunavir.

Conclusion: Genotype evolution within the protease region did not emerge at significant levels during salvage therapy of multidrug-experienced patients. ATV exhibited certain/same virologic effect on the majority of our patients.
\end{abstract}

(C) 2007 Elsevier B.V. All rights reserved.

Keywords: HIV-1; Atazanavir; Drug resistance; Viral evolution; Phylogenesis

\section{Introduction}

Atazanavir (ATV) is a novel azapeptide protease inhibitor. It has recently been approved by the FDA/EMEA for the treatment of HIV infection, and its pharmacokinetic profile makes it the first PI that can be administered once daily (Robinson et al., 2000). ATV can be used in combination with other drugs as first-line treatment or as salvage therapy (Musial et al., 2004; De Mendoza et al., 2006).

ATV offers some important advantages, as favourable metabolic toxicity profile (lipid and glucidic metabolism)

\footnotetext{
* Corresponding author. Tel.: +3902 39042668; fax: +39 0250319758.

E-mail address: stefano.rusconi@unimi.it (S. Rusconi).
}

(Fuster and Clotet, 2005; Johnson et al., 2006a,b; Noor et al., 2006; Mallolas et al., 2007).

The mutation I50L appeared to decrease affinity of the enzyme for ATV while increasing the affinity for other PI (Yanchunas et al., 2005). Eight PI mutations (10F/I/V, 16E, $33 \mathrm{I} / \mathrm{F} / \mathrm{V}, 46 \mathrm{I} / \mathrm{L}, 60 \mathrm{E}, 64 \mathrm{~V}, 85 \mathrm{~V}$ and $90 \mathrm{M}$ ) were described to affect the clinical response to ATV/rtv. All patients showed a virologic response to ATV when 2 or less mutations were present, independently of the background regimen (Vora et al., 2006).

Genotypic analysis of phenotypically selected resistant viruses to ATV showed presence of amino acid substitution in the viral protease $(\mathrm{A} 71 \mathrm{~V}, \mathrm{~N} 88 \mathrm{~S}, \mathrm{I} 84 \mathrm{~V})$ and based on new data minor mutations were added to ATV (with or 
without boosting with low-dose ritonavir) (Johnson et al., 2006a,b).

The aim of this study was to evaluate the evolution of resistance associated mutations located in the region of the protease enzyme, after administration of ATV.

\section{Materials and methods}

Ten HIV-1 infected patients in HAART therapy followed up in our Institute were enrolled in this study. At screening, nine patients were failing their current regimen and one had pharmacological intolerance, with serious associated side effects. One out of nine had cardiovascular risk factors in his clinical history.

All patients gave informed consent to participate to this approved study, by the Institutional Review Board of Luigi Sacco Hospital, University of Milan.

Genotype of viral isolates was performed from plasma samples at the first drug administration time $\left(\mathrm{M}_{0}\right)$ and at 3, 6, 9 and 12 months, when available. HIV-RNA was extracted and the $p o l$ region was amplified by nested RT-PCR, as previously described (Najera et al., 1995; Rusconi et al., 1997, 2000; Drusano et al., 1998).

The obtained genotypic profiles were used for the phylogenetic analysis. Such as to evaluate the evolution of different viral strains during the treatment. The consensus sequence of HIV-1 subtype A, derived from Los Alamos data bank, was used as reference clade of the phylogenetic tree. We chose to root the tree according to a strain which was not close to the sequences analysed: as all the sequences belonged to subtype B, a subtype A was chosen as root. Other subtype B sequences from the same laboratory were used as control for contamination. Sequences alignment of gene fragments was done automatically by Clustal X program 1.8 version.

ATV viral susceptibility data were obtained by Virtual Phenotype using VircoNET ${ }^{\mathrm{TM}} 1.6 .7$ version, that compare real geno-phenotypic data to consensus sequences deposited in the Virco data bank (Virco BVBA, Mechelen, Belgium).

Genotypic susceptibility scores (GSS) and viral drug susceptibility were calculated by a computer program (HIVdb, Stanford University, CA, USA), that uses available mutation scoring tables based on published literature (Rhee et al., 2003). The GSS was calculated by summing up scores of different drugs (Kantor et al., 2004).

The nucleotide sequences have been submitted to GenBank: accession numbers EF526180-EF526209.

\section{Results}

\subsection{Patients baseline features}

Data are summarized in Table 1 . To 8 of 10 patients was assigned a lower genotypic susceptibility score $(<1.75)$, whereas 2 of 10 showed a higher GSS. The median CD $4^{+}$

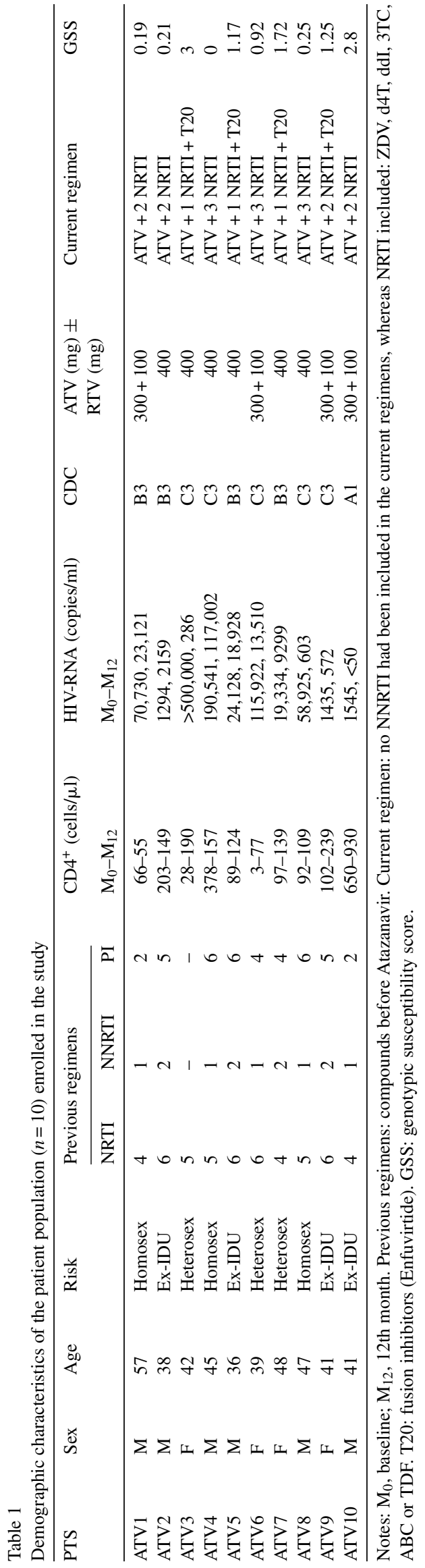


cell count at start of study was 94.50/ $\mu 1$ (IQR: 66.00-203.00) and the median plasma HIV-1 RNA was 41,526.50 copies $/ \mathrm{ml}$ (IQR: 1545.00-115,922.00).

\subsection{Viral load in Atazanavir-treated patients}

In patients ATV3 and ATV10, there was a constant reduction over time of 3 and $1.5 \log (<50 \mathrm{cp} / \mathrm{ml}$ in ATV10), respectively. Patient ATV1 also showed a decrease of about $0.5 \mathrm{log}$, followed by a slight increase at $\mathrm{M}_{12}$. Viral load in patients ATV2, ATV5, ATV6 and ATV7 remained substantially unchanged. Patients ATV4 and ATV9 showed an initial reduction followed by an increase in HIV-RNA, whereas the viral load of patient ATV8 increased since Atazanavir was started. In patient ATV9 the detection of HIV-RNA at $\mathrm{M}_{12}$ was followed by a constant viral suppression.

\subsection{Genotypic analysis}

The genotypic analysis revealed mutations in viral protease: some of these emerged after starting Atazanavir, including some major mutations such as I54V and I54A, G73S, and N88S, and some minor mutations, such as L33F and $\mathrm{A} 71 \mathrm{~V}$. Some others did not appear in different positions such as K20K/M, M36M/I, I47I/V and N88N/S. Genotype data are shown in Table 2

The resistance profile of the virus in patient ATV1 at $\mathrm{M}_{12}$ showed appearance of mutation I50L, which is characteristic of PI-naive patients taking ATV, but rare in pretreated patients. In patient ATV7, the mutation G48V was no longer detected.

The resistance profiles of patients ATV9 and ATV10 were only evaluated at $\mathrm{M}_{0}$ because their viral load decreased to $<50 \mathrm{cp} / \mathrm{ml}$ at the subsequent time points $\left(\mathrm{M}_{3}\right.$ and $\mathrm{M}_{6}$ in the case of ATV9, and $\mathrm{M}_{6}$ and $\mathrm{M}_{12}$ in the case of ATV10) and amplification of the samples failed.

\subsection{Phenotypic analysis}

Table 2 shows the data related to the phenotypic analysis made using Virtual Phenotype. Patients ATV1 and ATV8 showed likely resistance to Atazanavir throughout the observation period, whereas patient ATV2 developed resistance over time. Patients ATV3, ATV4 and ATV6 maintained a stable response to the drug. Finally, the resistance profiles of patients ATV5 and ATV7 improved over time showing a decrease in the IC50 fold-change. Viral phenotype of ATV9 and ATV10 was not determined, due to negative cell culture.

\subsection{Phylogenetic analysis}

To explore the genetic diversity of HIV-1 we analyzed all available sequences. Patients ATV9 and ATV10 were not included in the phylogenetic analysis as their viral load dropped at $<50 \mathrm{cp} / \mathrm{ml}$ after starting the ATV regimen.

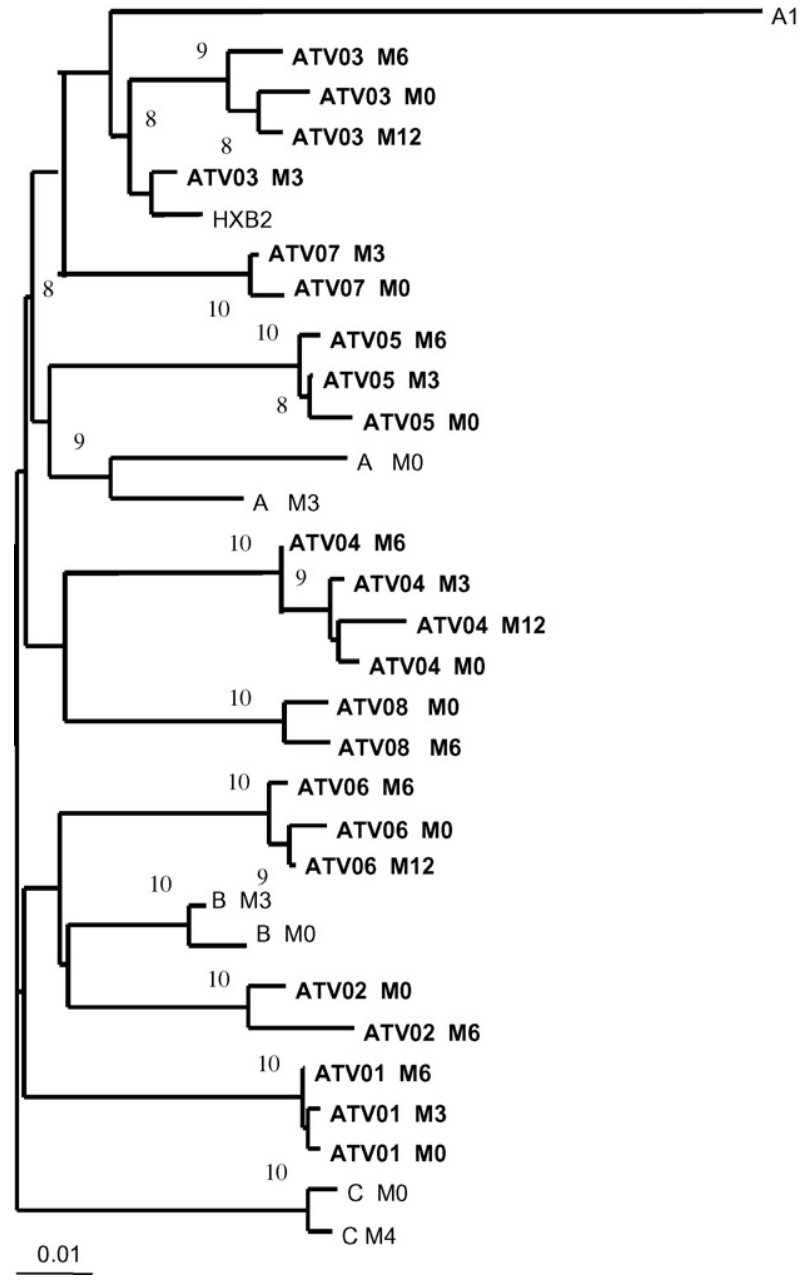

Fig. 1. Neighbor-joining phylogenetic tree of pol sequences. Kimura-2 parameter. transition/transversion ratio: 2.00. Showing bootstrap values $>75 \%$ only. Consensus of subtype A strains (A1) was used as an outgroop. Laboratory HIV-1 strain such as HXB2 and patients' sequences from the Sacco Hospital ( $\mathrm{A} \mathrm{M}_{0}$ and $\mathrm{M}_{3}, \mathrm{~B} \mathrm{M}_{0}$ and $\mathrm{M}_{3}, \mathrm{C} \mathrm{M}_{0}$ and $\mathrm{M}_{4}$ ) were used as controls. The distance between two individual sequences can be derived by comparing the length of the horizontal branches separating the sequences to the scale bar.

All patients were infected with subtype B strains and sequences showed the expected patient-specific clustering. The temporal analysis of pol sequences showed limited evolution between the first and the last available sequence for each patient suggesting that the overall genetic evolution was extremely limited for these patients. The sequences at later time points did not accumulate a significant number of mutations and diverge a lot from the baseline sequences, suggesting that there may be a bias against newly emerging protease variants (Fig. 1).

\section{Discussion}

We studied a cohort of HIV-positive patients characterised by multiple therapeutic failures or pharmacological intol- 
Table 2

Genotypic resistance profiles in the plasma compartment and ATV, TPV, DRV Virtual Phenotype

\begin{tabular}{|c|c|c|c|c|c|c|}
\hline \multirow{2}{*}{$\frac{\text { PTS }}{\text { ATV1 }}$} & & \multicolumn{2}{|l|}{ Time } & \multicolumn{3}{|l|}{ Genotype profile } \\
\hline & & \multicolumn{2}{|l|}{$\begin{array}{l}\mathrm{M}_{0} \\
\mathrm{M}_{3} \\
\mathrm{M}_{6} \\
\mathrm{M}_{12}\end{array}$} & \multicolumn{3}{|c|}{$\begin{array}{l}\text { L10F, L24I, L33F, M46I, I54V, L63P, A71V, G73S, V77I, V82A, N88N/S } \\
\text { L10F, L24I, L33F, M46I, I50L, I54V, L63P, A71V, G73S, V77I, V82A }\end{array}$} \\
\hline ATV2 & & \multicolumn{2}{|l|}{$\begin{array}{l}\mathrm{M}_{0} \\
\mathrm{M}_{6} \\
\mathrm{M}_{12}\end{array}$} & \multicolumn{3}{|c|}{$\begin{array}{l}\text { L10F, K20R, L33F, M36I, I54V, L63P, A71V, V82A, I84V, L90M } \\
\text { L10F, K20R, L33F, I54V, L63P, A71V, G73S, I84V, L90M } \\
\text { K20R, L33F, M36I, I54V, L63P, A71V, G73S, V82A, I84V, L90M }\end{array}$} \\
\hline ATV3 & & \multicolumn{2}{|l|}{$\begin{array}{l}\mathrm{M}_{0} \\
\mathrm{M}_{3} \\
\mathrm{M}_{6} \\
\mathrm{M}_{12}\end{array}$} & $\begin{array}{l}\text { L63P } \\
\text { L63P } \\
\text { M36M/I } \\
\text { L63P }\end{array}$ & & \\
\hline ATV4 & & \multicolumn{2}{|l|}{$\begin{array}{l}\mathrm{M}_{0} \\
\mathrm{M}_{3} \\
\mathrm{M}_{6} \\
\mathrm{M}_{12}\end{array}$} & \multicolumn{3}{|c|}{$\begin{array}{l}\text { L10I, M36I, L63P, A71V, V82A, I84V, L90M } \\
\text { L10I, M36I, I54V, L63P, A71V, V82A, I84V, L90M } \\
\text { L10L/I, K20K/M M36M/I, I54V, L63P, A71V, V82A, I84I/V, L90M } \\
\text { L10I, M36I, I54V, L63P, A71V, V82T, I84V, L90M }\end{array}$} \\
\hline ATV5 & & \multicolumn{2}{|l|}{$\begin{array}{l}\mathrm{M}_{0} \\
\mathrm{M}_{3} \\
\mathrm{M}_{6} \\
\mathrm{M}_{12}\end{array}$} & \multicolumn{3}{|c|}{$\begin{array}{l}\text { L10I, M46L, I54V, L63P, V77I, I84V, L90M } \\
\text { L10I, M46L, I54V, L63P, A71V, V77I, I84V, L90M } \\
\text { L10I, M46L, I54V, L63P, A71V, G73S, V77I, I84V, L90M } \\
\text { L10I, L33F, M46L, I54A, L63P, A71V, V77I, I84V, L90M }\end{array}$} \\
\hline ATV6 & & \multicolumn{2}{|l|}{$\begin{array}{l}\mathrm{M}_{0} \\
\mathrm{M}_{6} \\
\mathrm{M}_{9}\end{array}$} & \multicolumn{3}{|c|}{$\begin{array}{l}\text { L10I, K20R, L33F, M36I, I54V, L63P, A71V, G73S, V82A, L90M } \\
\text { L10I, K20R, L33L/F, M36I, I54V, L63P, A71V, G73G/S, V82A, L90M } \\
\text { L10I, K20R, L33F, M36I, I54V, L63P, A71V, G73S, V82A, L90M }\end{array}$} \\
\hline ATV7 & & \multicolumn{2}{|l|}{$\begin{array}{l}\mathrm{M}_{0} \\
\mathrm{M}_{3} \\
\mathrm{M}_{12}\end{array}$} & \multicolumn{3}{|c|}{$\begin{array}{l}\text { L10I, M46L, G48V, I54V, L63P, A71T, V82A } \\
\text { L10I, M46L, G48V, I54V, L63P, A71T, V82A } \\
\text { L10I, M46L, I54V, L63P, A71T, V82A }\end{array}$} \\
\hline ATV8 & & \multicolumn{2}{|l|}{$\begin{array}{l}\mathrm{M}_{0} \\
\mathrm{M}_{6} \\
\mathrm{M}_{12}\end{array}$} & \multicolumn{3}{|c|}{$\begin{array}{l}\text { L10I, K20R, V32I, L33F, M36I, I47V, L63P, A71V, V82T, L90M } \\
\text { L10I, K20R, V32I, L33F, M36I, I47I/V, L63P, A71V, V82T, L90M } \\
\text { L10I, K20R, V32I, L33F, M36I, I54A, L63P, A71V, V82T, L90M }\end{array}$} \\
\hline ATV9 & & \multicolumn{2}{|l|}{$\begin{array}{l}\mathrm{M}_{0} \\
\mathrm{M}_{3} \\
\mathrm{M}_{6}\end{array}$} & \multicolumn{3}{|c|}{$\begin{array}{l}\text { L10F, K20R, V32I, M36I, M46I, I47V, I54M, L63P, A71V, V82A, L90M } \\
\text { / }\end{array}$} \\
\hline ATV10 & & \multicolumn{2}{|l|}{$\begin{array}{l}\mathrm{M}_{0} \\
\mathrm{M}_{6} \\
\mathrm{M}_{12}\end{array}$} & \multicolumn{3}{|c|}{$\begin{array}{l}\text { L10I, L63P, V77I } \\
/ \\
/\end{array}$} \\
\hline $\begin{array}{l}\text { ATV FC } \\
\text { (IC50) }\end{array}$ & $\begin{array}{l}\text { ATV CCO1-CCO2 } \\
\text { interpretation }\end{array}$ & & $\begin{array}{l}\text { TPV FC } \\
\text { (IC50) }\end{array}$ & $\begin{array}{l}\text { TPV CCO1-CCO2 } \\
\text { interpretation }\end{array}$ & $\begin{array}{l}\text { DRV FC } \\
(\text { IC50) }\end{array}$ & $\begin{array}{l}\text { DRV CCO1-CCO2 } \\
\text { interpretation }\end{array}$ \\
\hline 13.4 & Partially resistant & & 0.5 & Susceptible & 1.6 & Susceptible \\
\hline 21.2 & Partially resistant & & 0.7 & Susceptible & 1.2 & Susceptible \\
\hline 54.0 & Resistant & & 0.6 & Susceptible & 0.9 & Susceptible \\
\hline 112.1 & Resistant & & 0.5 & Susceptible & 0.6 & Susceptible \\
\hline 24.7 & Partially resistant & & 4.2 & Partially resistant & 4.7 & Partially resistant \\
\hline 54.5 & Resistant & & 4.9 & Partially resistant & 7.6 & Partially resistant \\
\hline 32.6 & Partially resistant & & 7.0 & Resistant & 4.0 & Partially resistant \\
\hline 0.7 & Susceptible & & 0.9 & Susceptible & 0.6 & Susceptible \\
\hline 0.6 & Susceptible & & 0.9 & Susceptible & 0.6 & Susceptible \\
\hline 0.5 & Susceptible & & 0.9 & Susceptible & 0.5 & Susceptible \\
\hline 0.5 & Susceptible & & 0.9 & Susceptible & 0.6 & Susceptible \\
\hline 31.7 & Partially resistant & & 5.5 & Resistant & 6.7 & Partially resistant \\
\hline 22.8 & Partially resistant & & 5.6 & Resistant & 6.6 & Partially resistant \\
\hline 11.0 & Partially resistant & & 2.2 & Partially resistant & 1.9 & Susceptible \\
\hline 36.6 & Resistant & & 12.0 & Resistant & 5.1 & Partially resistant \\
\hline 24.7 & Partially resistant & & 3.1 & Susceptible & 1.3 & Susceptible \\
\hline 15.8 & Partially resistant & & 3.4 & Susceptible & 1.5 & Susceptible \\
\hline 31.0 & Partially resistant & & 2.3 & Susceptible & 1.8 & Susceptible \\
\hline 38.7 & Resistant & & 28.9 & Resistant & 5.6 & Partially resistant \\
\hline 143.4 & Resistant & & 2.1 & Partially resistant & 1.8 & Susceptible \\
\hline 18.8 & Partially resistant & & 1.1 & Susceptible & 0.7 & Susceptible \\
\hline
\end{tabular}


Table 2 (Continued)

\begin{tabular}{llllll}
\hline $\begin{array}{l}\text { ATV FC } \\
\text { IC50) }\end{array}$ & $\begin{array}{l}\text { ATV CCO1-CCO2 } \\
\text { interpretation }\end{array}$ & $\begin{array}{l}\text { TPV FC } \\
\text { (IC50) }\end{array}$ & $\begin{array}{l}\text { TPV CCO1-CCO2 } \\
\text { interpretation }\end{array}$ & $\begin{array}{l}\text { DRV FC } \\
\text { (IC50) }\end{array}$ & $\begin{array}{l}\text { DRV CCO1-CCO2 } \\
\text { interpretation }\end{array}$ \\
\hline 96.1 & Resistant & 2.1 & Partially resistant & 1.8 & Susceptible \\
26.6 & Partially resistant & 0.6 & Susceptible & 0.7 & Susceptible \\
11.7 & Partially resistant & 0.5 & Susceptible & 0.7 & Susceptible \\
4.1 & Partially resistant & 1.4 & Partially resistant & 0.8 & Susceptible \\
37.8 & Resistant & 19.6 & Resistant & 4.1 & Partially resistant \\
27.1 & Partially resistant & 16.6 & Resistant & 4.2 & Partially resistant \\
37.7 & Resistant & 18.6 & Resistant & 4.1 & Partially resistant \\
14.6 & Partially resistant & 0.8 & Susceptible & 5.4 & Partially resistant \\
n.a. & - & n.a. & - & n.a. & - \\
n.a. & - & n.a. & - & n.a. & - \\
0.5 & Susceptible & 0.7 & Susceptible & 0.5 & Susceptible \\
n.a. & - & n.a. & - & n.a. & n.a \\
n.a. & - & n.a & - & - \\
\hline
\end{tabular}

Notes: PTS, patients; $\mathrm{M}_{0}$, baseline; $\mathrm{M}_{3}$, 3rd month; $\mathrm{M}_{6}$, 6th month; $\mathrm{M}_{9}$, 9th month; $\mathrm{M}_{12}$, 12th month. Bold character: mutations not present at $\mathrm{t}_{0}$; italic character: mutations differing only in terms of the highlighted amino acid; /: not evaluable (HIV-RNA $<50 \mathrm{cp} / \mathrm{ml}$ ). FC in IC 50 (fold-change inhibitory concentration $50 \%$ ): calculated with reference to a wild-type virus, according the Virconet explanation; n.a.: not available. CCO: clinical cut-off values; $\mathrm{CCO} 1$ : baseline $\mathrm{FC}$ in $\mathrm{IC}_{50}$, susceptible which the virologic response to a drug is expected to be similar to that of a wild-type virus (loss of 20\% of response); $\mathrm{CCO}_{2}$ : $\mathrm{FC}_{\text {in }} \mathrm{IC}_{50}$, above which most virologic response to the drug is expected to be lost due to resistance (loss of $80 \%$ of response). ATV5: Atazanavir was replaced by another PI (tipranavir) during the 10th month of treatment.

erance and unbalanced lipid and glucidic profile. Our aim was to analyse the evolution of the mutations located in the region of the protease enzyme that lead to resistance to PIs following the administration of Atazanavir. Previous studies showed that baseline phenotypic susceptibility had a role on the response to PI treatment (Naeger and Struble, 2006).

The genotypic resistance analysis (Table 2) revealed only few new mutations (I50L, I54V, A71V, G73S and N88N/S) conferring resistance to Atazanavir. These mutations do not induce cross-resistance to other protease inhibitors (except minor mutation G73S that confers resistance to darunavir boosted with ritonavir). Two of 10 patients had a similar FC profile, whereas 8 of 10 showed a higher sensitivity of TPV and DRV compared to ATV. This was more evident for the last compound since there was less concordance between ATVrelated and DRV-related mutations in our samples. In the quest of the ideal antiretroviral therapy regimen, there is an emerging issue regarding the sequentiability from ATV to TPV or DRV.

In particular, patient ATV1 developed the N88N/S mutation over time, and the $\mathrm{I} 50 \mathrm{~L}$ mutation at $\mathrm{M}_{12}$. This substitution conferring resistance to Atazanavir is characteristic of PI-naive patients, but is very rare in pretreated patients (Noor et al., 2006). Comparison of viruses bearing I50L with those bearing I50V revealed specific resistance to Atazanavir and Amprenavir (APV), respectively, with no evidence of cross-resistance (Colonno et al., 2004; Weinheimer et al., 2005). The HIV-protease enzyme from multi-experienced subjects is already largely mutated and therefore considerably stiff, one of the reasons for the rarity of mutation I50L in subjects who have accumulated multiple resistances to PIs. Furthermore, the enzyme itself would not benefit from the acquisition of a new mutation in position 50, a finding that seems to correlate well with the patient's phenotypic susceptibility (Table 2). The trend of viral load also highlighted an increase in replication as from $\mathrm{M}_{6}$, when mutation N88N/S appeared and was followed by I50L.

Moreover, ATV5 analysis of genotypic resistances highlighted the loss of mutation $\mathrm{G} 73 \mathrm{~S}$ at $\mathrm{M}_{6}$ and appearance of L33F. This was probably due to the fact that the patient stopped taking ATV in the 10th month of treatment (i.e. 2 months before the $\mathrm{M}_{12}$ sample) and switched to a different PI (TPV) (Schapiro et al., 2005; The RESIST 2 and RESIST 1 Study Teams, 2006), as mutation L33F is known as TPVinduced modification (Valdez et al., 2005).

The infectivity of viruses was tested: there was a constant decrease in viral titration values over time.

Our data confirm that ATV should be boosted when used in multidrug-experienced patients, nevertheless several studies demonstrated a favourable lipid profile of boosted-ATV both at 48 and 96 weeks (Johnson et al., 2006a,b; Mallolas et al., 2007).

Finally, phylogenetic analysis of the protease sequences demonstrated a limited evolution of the viral variants during ATV therapy: it is possible that occurrence of variants resistant to ATV requires a very high price in terms of fitness, as the lower replicative capacity of the strains harbouring $150 \mathrm{~L}$, G73S and N88S seems to suggest.

In conclusion, ATV exhibited a certain virologic effect on the majority of our patients, thus subjects with multiple therapeutic failures with or without an increased cardiac risk had taken advantage from ATV-containing therapies with a minimal evolutionary cost. In this clinical setting, ATV use would be advantageous in multiple failed subjects without accelerating HIV-1 evolution.

\section{Acknowledgements}

We acknowledge the continuous support of Elizabeth L. Kaplan, M.S.W. This work was supported by AIDS research 
grants (III, IV and V AIDS Project) from the Istituto Superiore di Sanita', Rome to S.R., the Andrea and Libi Lorini Foundation, Milan to M.L.C., and Anlaids ONLUS Sez. Lombarda, Milan, Italy. We thank Professor Mauro Moroni for the priceless discussions and guidance.

\section{References}

Colonno R, Rose R, McLaren C, Thiry A, Parkin N, Friborg J. Identification of I50L as the signature atazanavir (ATV)-resistance mutation in treatment-naive HIV-infected patients receiving ATV-containing regimens. J Infect Dis 2004;189:1802-10.

De Mendoza C, Valer L, Ribera E, Barreiro P, Martin-Carbonero L, Ramirez G, et al. Performance of six different ritonavir-boosted protease inhibitor-based regimens in heavily antiretroviral-experienced HIV-infected patients. HIV Clin Trials 2006;7:163-71.

Drusano GL, Bilello JA, Stein DS, Nessly M, Meibohm A, Emini EA, et al. Factors influencing the emergence of resistance to indinavir: role of virologic, immunologic and pharmacologic variables. J Infect Dis 1998;178:360-7.

Fuster D, Clotet B. Review of atazanavir: a novel HIV protease inhibitor. Expert Opin Pharmacother 2005;6:1565-72.

Johnson M, Grinsztejn B, Rodriguez C, Coco J, DeJesus E, Lazzarin A, et al. 96-week comparison of once-daily atazanavir/ritonavir and twice-daily lopinavir/ritonavir in patients with multiple virologic failures. AIDS 2006a;20:711-8.

Johnson VA, Brun-Vezinet F, Clotet B, Kuritzkes DR, Pillay D, Schapiro JM, et al. Update of the Drug Resistance Mutations in HIV-1: Fall 2006. Top HIV Med 2006b;14:125-30.

Kantor R, Shafer RW, Follansbee S, Taylor J, Shilane D, Hurley L, et al. Evolution of resistance to drugs in HIV-1-infected patients failing antiretroviral therapy. AIDS 2004;18:1503-11.

Mallolas J, Podzamczer D, Domingo P, Clotet B, Ribera E, Gutierrez F, et al. Efficacy and safety of switching from lopinavir/r (LPV/r) to atazanavir/r (ATV/r) in patients with virologic suppression receiving a LPV/r containing HAART: The ATAZIP study. In: 4th IAS Conference; 2007 [abstract A-042-0096-05499].

Musial BL, Chojnacki JK, Coleman CI. Atazanavir: a new protease inhibitor to treat HIV infection. Am J Health Syst Pharm 2004;61:1365-74.

Naeger LK, Struble KA. Effect of baseline protease genotype and phenotype on HIV response to atazanavir/ritonavir in treatment-experienced patients. AIDS 2006;20:847-53.

Najera I, Holguin A, Quinones-Mateu ME, Munoz-Fernandez MA, Najera R, Lopez-Galindez C, et al. pol Gene quasispecies of human immunodeficiency virus: mutations associated with drug resistance in virus from patients undergoing no drug therapy. J Virol 1995;69:23-31.
Noor MA, Flint OP, Maa JF, Parker RA. Effects of atazanavir/ritonavir and lopinavir/ritonavir on glucose uptake and insulin sensitivity: demonstrable differences in vitro and clinically. AIDS 2006;20:1813-21.

Rhee SY, Gonzales MJ, Kantor R, Betts BJ, Ravela J, Shafer RW. Human immunodeficiency virus reverse transcriptase and protease sequence database. Nucleic Acids Res 2003;31:298-303.

Robinson BS, Riccardi KA, Gong YF, Guo Q, Stock DA, Blair WS, et al. BMS-232632, a highly potent human immunodeficiency virus protease inhibitor that can be used in combination with other available antiretroviral agents. Antimicrob Agents Chemother 2000;44: 2093-9.

Rusconi S, De Pasquale MP, Milazzo L, Moscatelli G, Bulgheroni E, Citterio $\mathrm{P}$, et al. Loss of antiviral effect owing to zidovudine and lamivudine double resistance in HIV-1 infected patients in an ongoing open label trial. Antiviral Ther 1997;2:41-8.

Rusconi S, La Seta Catamancio S, Citterio P, Kurtagic S, Violin M, Balotta C, et al. Susceptibility to PNU-140690 (tipranavir) of human immunodeficiency virus type 1 isolates derived from patients with multidrug resistance to other protease inhibitors. Antimicrob Agents Chemother 2000;44:1328-32.

Schapiro J, Cahn P, Trottier B, Antunes F, Jayaweera D, Gerstoft J, et al. Effect of baseline genotype on response to Tipranavir/ritonavir $(\mathrm{TPV} / \mathrm{r})$ compared with standard-of-care comparator in treatmentexperienced patients: the phase 3 RESIST-1 and-2 trials. In: 12th Conference on Retroviruses and Opportunistic Infections; 2005 [abstract 104].

The RESIST 2 and RESIST 1 Study Teams. Tipranavir achieves twice the rate of treatment response and prolongs durability of response vs. comparator PI in antiretroviral therapy experienced patients, independent of baseline CD 4 cell count or viral load: week 48 RESIST 1 and 2 combined analyses. In: 13th Conference on Retroviruses and Opportunistic Infections; 2006 [abstract 520].

Valdez H, Hall DB, Kohlbrenner VM, Boucher CA, Schapiro J, Baxter J, et al. Non-response to tipranavir is associated with pretreatment resistance characterized by tipranavir phenotype or genotypic tipranavir score. Antivir Ther 2005;10:S29.

Vora S, Marcelin AG, Gunthard HF, Flandre P, Hirsch HH, Masquelier B, et al. Clinical validation of atazanavir/ritonavir genotypic resistance score in protease inhibitor-experienced patients. AIDS 2006;20:35-40.

Weinheimer S, Discotto L, Friborg J, Yang H, Colonno R. Atazanavir signature $\mathrm{I50 \textrm {L }}$ resistance substitution accounts for unique phenotype of increased susceptibility to other protease inhibitors in a variety of human immunodeficiency virus type 1 genetic backbones. Antimicrob Agents Chemother 2005;49:3816-24.

Yanchunas Jr J, Langley DR, Tao L, Rose RE, Friborg J, Colonno RJ, et al. Molecular basis for increased susceptibility of isolates with atazanavir resistance-conferring substitution $\mathrm{I50 \textrm {L }}$ to other protease inhibitors. Antimicrob Agents Chemother 2005;49:3825-32. 